\title{
Sebastián Salazar Bondy y la utopía del socialismo mágico: revisitando El rabdomante
}

\section{Sebastián Salazar Bondy and the utopia of magical socialism: revisiting El rabdomante}

Carlos Vargas Salgado ${ }^{1}$

Whitman College. Washington, Estados Unidos

vargasca@whitman.edu

\section{RESUMEN}

Este artículo explora la última obra escrita por el extaordinario dramaturgo peruano Sebastián Salazar Bondy (1924-1965). En El rabdomante, un país de «miserables» que enfrentan la opresión y la injusticia son guiados por una especie de chamán capaz de encontrar agua y con ella la independencia política. Leída frecuentemente como una alegoría a la violencia social en el Perú, El rabdomante también es una meditación sobre los vicios y las virtudes de los proyectos socialistas en la década de 1960 en países como el Perú. Esta obra teatral revela con claridad los intereses estéticos y políticos que dominaron la obra completa de Salazar Bondy, y debería recibir mayor atención al calor de las actuales discusiones sobre el pensamiento decolonial en América Latina.

\section{PALABRAS CLAVE}

Sebastián Salazar Bondy, literature peruana, teatro peruano, socialismo en Latinoamérica

\section{ABSTRACT}

This article explores the final play written by Sebastián Salazar Bondy (1924-1965), the prominent Peruvian playwright. In El rabdomante («The Water Diviner») a country

1 Profesor de Teatro y Estudios de Performance en Whitman College de Washington, Estados Unidos. Obtuvo un PhD en Literatura Hispánica por la Universidad de Minnesota, Twin Cities, con una tesis sobre el teatro peruano durante el tiempo de la violencia política. Sus trabajos han sido publicados en revistas del Perú, Estados Unidos, España, Brasil, entre otros países. Es miembro de la International Brecht Society, la American Society for Theatre Research y la Asociación Internacional de Teatro del Siglo XXI. 
of «the dispossessed», facing oppression and injustice, is guided by a shaman able to lead them to water, and with it political independence. Frequently read as an allegory of the social violence experienced by Peru, El rabdomante is also a meditation on the virtues and vices of the country's socialist projects of the 1960s. The play reflects with clarity the political and aesthetic concerns that dominate Salazar Bondy's entire oeuvre, and is deserving of greater attention within the context of contemporary discussion surrounding decolonial thought in Latin America.

\section{KEYWORDS}

Sebastián Salazar Bondy, Peruvian literature, Peruvian drama, socialism in Latin America

Hacia 1964, Sebastián Salazar Bondy comienza a redactar —acaso sin saberlo - su propio testamento intelectual. En los febriles meses que seguirían, entre viajes, conferencias que han devenido legendarias (el Encuentro de Narradores en Arequipa, la Mesa Redonda sobre Todas las sangres) y una vibrante labor periodística, Salazar Bondy publicaría Lima la horrible, su manifiesto de anticolonialidad, al mismo tiempo que emprende la escritura del drama El rabdomante, una suerte de obra didáctica sobre la descolonización en la que unos hombres subhumanos rompen a golpes la estructura del poder que los oprime, de la mano de un mago que no sobrevive su propia gesta. Tampoco Salazar Bondy sobrevive a la suya. Salazar Bondy muere de forma intempestiva en Lima en 1965 a los 41 años. Y aunque su breve paso por la vida nos ha dejado textos memorables, muchos de ellos son algo mejor que eso: son textos para la memoria, o para la anticipación del porvenir.

Desde hace unos años, y con motivo de conmemorar 50 años de su prematura muerte, el interés por la obra del autor limeño creció exponencialmente, en particular a través de reediciones de sus obras y antologías sobre su trabajo periodístico². Sin embargo, queda mucho por elucidar en la obra de Salazar Bondy. Uno de los temas por resolver con mayor solvencia es el lugar que ocupó el teatro en la vida y obra del autor, tema extenso por lo demás. En este trabajo me ocupo de discutir precisamente

2 Desde estudios sobre su obra en conjunto como el del francés Hirschhorn, Sebastián Salazar Bondy. Pasión por la cultura (2005), o la reciente edición (2004) que hizo la Universidad Nacional Mayor de San Marcos de la labor periodística de Salazar Bondy. Tampoco es menor el asunto de que la Universidad de Concepción en Chile haya reeditado y debatido Lima la horrible (2002). 
la última obra dramática de Sebastián Salazar Bondy, El rabdomante, tanto en su ubicación en la producción vinculada al teatro, como en su propia naturaleza de texto culminante de un interés central en la vida de Salazar.

\section{El lugar del teatro en la obra de Salazar Bondy}

Es indudable que el teatro fue columna vertebral de los intereses y de la obra creativa y crítica de Salazar Bondy. Hirschhorn (2005) ha contabilizado más de 200 artículos dedicados al teatro en 25 años de labor periodística, el primero de los cuales, también el más antiguo del que se tiene noticia, lleva como título simple "El teatro" (Jornada, 19 de julio de 1940, citado por Hirschhorn). El corpus de su producción dramática, por otra parte, incluye 15 títulos entre dramas, comedias y juguetes (obras cómicas breves). De acuerdo con Hirschhorn, existen además tres obras inéditas y numerosas adaptaciones de autores extranjeros. Por ella mereció el Premio Nacional de Teatro en tres oportunidades $(1947,1952,1965)$. Sus relaciones con la escena viva, además, son numerosas y reveladoras: su ayuda a formar el Club de Teatro de Lima (junto con Reynaldo D'Amore, 1953), su trabajo junto a Inda Ledesma, actriz y su primera esposa (1947-1951), la reorganización del área de Teatro del Ministerio de Educación (1951), su trabajo de dramaturgista para la compañía de Pedro López Lagar (1952), sus estudios de Teatro en el Conservatoire National Supérieur d'Art Dramatique de París (1956), su labor como profesor y director de la Escuela de Arte Escénico (desde 1954), su participación como jurado del Premio Casa de las Américas (Cuba) en el área de teatro ${ }^{3}$. Su vida pública, como puede verse, es la de un hombre de teatro en pleno sentido del término.

Todo indica, además, que para Salazar Bondy el hecho de la escritura creativa o reflexiva sobre el arte del teatro estaba siempre y en todo lugar relacionada con la realidad. La realidad social y la realidad práctica de la escena en función de la cual escribía. En una inicial edición de sus Seis juguetes (1958), luego de dedicar sus obras a grupos juveniles y actores que inician, Salazar Bondy declara:

[estas obras] intentan ser expresión del primordial anhelo de recrear en el tablado hechos que [...] son manifestaciones de la realidad del hombre y su circunstancia, aquí y ahora (Salazar Bondy, 1958, p. 6).

La obra teatral es espejo de la sociedad tanto como práctica festiva, juvenil, que requiere incentivo y expansión en la comunidad. El ideario teatral del autor supone no plantear barreras entre la escritura y la conexión con la comunidad; antes bien, la escritura supone una voz que encuentra

3 Para una revisión de la cronología, ver Quispe, 2015. 
su modo adecuado únicamente en su vínculo con el grupo. Por ello, su constante preocupación como crítico, por ejemplo, en la necesidad de educar al lector-espectador, así como de reclamar al Estado por la difusión de formas artísticas entre la comunidad.

De esta forma, esta amplitud de miras de Salazar Bondy en relación con el teatro también lo hace por demás singular. En un momento en que el teatro peruano se debatía entre los escritores que abogaban por un teatro para leer, o que afirmaban que lo literario era el centro de la experiencia estética en el teatro ${ }^{4}$, Salazar Bondy se muestra muy avanzado en apertura:

Un balance del teatro de estos días exige que sean examinados por rubros los diversos aspectos de la creación dramática, que es, bien se sabe, creación colectiva, no solo de los intérpretes entre sí, sino del espectáculo con su público [...] lo que es indivisible, una totalidad, un hecho fluido y unitario (Salazar Bondy, citado por Joffré, 1993, p. 11).

Desde luego, su aporte como dramaturgo al teatro nacional es sin duda fundamental. Como recuerda José Miguel Oviedo, "fue uno de los pocos, quizá el único, que tuvo una conciencia profesional del teatro" $(1967$, p. 9) El rigor con el que asumió su escritura para la escena, incluso desde las primeras obras de juventud, nos habla de una vocación temperada con la exigencia técnica. Salazar Bondy escribía textos dramáticos cuando el medio teatral resultaba aún poco profesional, tal como menciona frecuentemente en sus artículos de diario (Hirschhorn).

Como ha recordado numerosas veces la autora Sara Joffré, Salazar Bondy resultó un eje fundamental para la creación de una conciencia nacional en la dramaturgia peruana. La ardorosa defensa de la necesidad de contar con repertorios de autor nacional, su probada dedicación, impulso y ayuda a nuevos autores (como la propia Joffré) sirvió como motor para las generaciones venideras, cuando "se empieza recién a aceptar, a jugar, con el matrimonio de las dos palabras: teatro peruano" (Joffré, 1993, p. 19).

Su propia obra dramática es un ejemplo de la necesidad y los desafíos que debía enfrentar la autoría dramática en el Perú que le tocó vivir. La obra dramatúrgica de Salazar Bondy transita vertiginosamente por varios registros, haciendo una suerte de balance del teatro en habla hispana hasta ese momento. Así, empezó por tomar elementos de la comedia clásica castellana, para luego releer el costumbrismo, abrirse al realismo norteamericano o finalmente dialogar con el teatro de vanguardia expresionista

4 Para una discusión sobre estas posiciones encontradas en la experiencia de escritura, ver mi trabajo Autores o dramaturgos (2015). 
y brechtiano. En un estudio inicial (1975), Juan Caballero clasifica las obras dramáticas de Salazar en cinco grupos: teatro poético (Amor gran laberinto), teatro costumbrista (El fabricante de deudas, Dos viejas van por la calle, La escuela de los chismes), teatro histórico (Rodil, Flora Tristán), teatro realista sobre la clase media (Algo que quiere morir, No hay isla feliz, Solo una rosa) y completa el cuadro con los atisbos de un teatro simbólico, expresionista en El rabdomante.

A pesar de lo problemático de seguir sosteniendo una división tajante en la producción dramática de Salazar Bondy, el periplo que narra Caballero es, a mi modo de ver, lo más destacable: el dramaturgo recorre en pocos años, y con un grupo impresionante pero no extenso de obras, varias de las coordenadas del teatro contemporáneo. Es paradigmático que Salazar Bondy comience imitando (en el sentido poético) el teatro clásico en español (se puede ver la impronta de Sor Juan Inés de la Cruz, en su drama Amor es más laberinto), para cerrar el arco con el mayor texto vanguardista que se ha escrito en el Perú hasta bien entrada la década de 1980, El rabdomante. La capacidad de experimentación dramatúrgica de Salazar Bondy es extraordinaria. Es como si se hubiera propuesto hacer evolucionar la expresión dramática peruana, en su propia obra, desde la clara influencia del teatro clásico español y traerla hacia un presente modernizado, abierto a las vanguardias.

Por ello, en el conjunto de la dramaturgia peruana del siglo XX, la obra de Salazar Bondy salta claramente a la vista como la más ambiciosa de un autor nacional. Mientras otros autores de su generación (Juan Ríos, Enrique Solari Swayne) se detienen en el teatro simbolista o realista, Salazar prosigue una ruta que lo llevará rápidamente al realismo psicologista, al teatro social y, finalmente, a la estética del absurdo. En paralelo, además, la veta de comediógrafo se mantiene intacta, y esto permite también que su obra nos entregue textos breves, altamente representables, hechos retomando la gran tradición de la comedia sencilla, que lo conecta con la tradición costumbrista peruana. También en esto, en el cultivo de la comedia como forma de discutir la sociedad, Sebastián Salazar Bondy resultó inusual, y en varios sentidos, único para el teatro peruano ${ }^{5}$.

5 No puedo dejar de mencionar aquí la aparente contradicción entre la importancia de Salazar Bondy para el teatro nacional y su poca visibilidad en el espectro del teatro peruano contemporáneo. Sin ánimo de cerrar la discusión, me animo a plantear que la prematura muerte del autor le impidió dejar su legado intelectual (teatral) completamente establecido. La inmediatez de su trabajo periodístico, y la repercusión mayor de su Lima la horrible, aunada a la desaparición repentina, crearon una imagen de Salazar Bondy como de un escritor excesivamente politizado. Desde luego, la llegada de la época de la violencia política tampoco abonó en favor de una obra abiertamente social(ista). 


\section{Utopías de socialismo mágico: El rabdomante}

El rabdomante (1964) cierra la labor dramatúrgica de Sebastián Salazar Bondy y se propone como culminación involuntaria de una obra dramática en constante mutación, plagada de múltiples influencias estéticas del teatro moderno de Occidente, acompasada con una clara postura cultural e ideológica, de revaloración de lo andino y de mostración de los problemas estructurales de la sociedad peruana. En ese sentido, es una pieza que representa bastante bien toda la experiencia dramática y política de Sebastián Salazar Bondy ${ }^{6}$.

Quizás por esta condición de finalización, de inesperado e infrecuente registro de escritura de un autor de gran influencia, El rabdomante haya sido objeto de variadas y a veces encontradas consideraciones e interpretaciones. Así, por ejemplo, de acuerdo con una temprana crítica de José Miguel Oviedo (1967, p. 32), la obra evidencia el comienzo de una nueva búsqueda que el autor no pudo desafortunadamente continuar. Aparece como una suerte de fusión de todas las experiencias escriturales anteriores de Salazar, en especial — sigue Oviedo_ - por la mezcla de realismo y simbología, alegoría y toques de absurdo y denuncia social. Sin embargo, a pesar de sus certeras intuiciones, Oviedo no esclarece (porque su trabajo intentaba ser un panorama general) qué elementos de El rabdomante podían ser análogos al absurdismo teatral.

Otras lecturas como la de Mario Vargas Llosa describen El rabdomante como un drama áspero, impregnado de símbolos y contenidos abstractos, pero que posee un gran acierto en el modo no realista que eleva la "historia hacia una zona más perenne y esencial" (1967, p. 27) También Wolfgang Luchting (1971, p. 88 y ss.), sostiene que se trata de una alegoría social, aunque se decanta afirmar que la obra forma parte de un corpus temático que plantea la suerte que corre el artista en la sociedad peruana. La lectura del personaje del rabdomante como alegoría al artista, si bien es posible, resulta forzada cuando se discuten los contenidos ideológicos de la obra, que son evidentes.

Por otro lado, Juan Caballero (1975, p. 103 y ss.) cree percibir en la obra una influencia de los esquemas del teatro del absurdo, por el registro de irrealidad que la espacialización y la caracterización proveen. Estas formas aparecerían por influencia de obras de autores franceses y alemanes, a

6 Salazar Bondy milita en el Movimiento Social Progresista desde 1955. Su inclinación izquierdista le había granjeado no pocas polémicas y dificultades. Una exposición detenida de su pensamiento social y político se encuentra en Escritos políticos y morales, editada por la Universidad Nacional Mayor de San Marcos en 2003. 
los que Salazar Bondy leía con suma dedicación $n^{7}$. Si el rabdomante acusa la influencia de los absurdistas europeos, ello sería más apreciable en el antirrealismo de la obra, y resultaría más problemático defender la idea al discutir el contexto social de opresión que la obra describe.

En una perspectiva radicalmente diferente se expresa Sara Joffré (1993, p. 21) cuando asevera que El rabdomante acusa el impacto e influencia de Brecht y el teatro dialéctico. Sin duda, Brecht era parte de las lecturas de Salazar, y es claro, a la luz de sus escritos críticos sobre teatro, que conocía de cerca la obra del autor alemán (quizás en francés), gracias a su viaje a Europa. Pero el teatro brechtiano como tal no influyó inmediatamente la obra de Salazar Bondy. Cuando regresa de Europa, la mayor parte de sus obras creadas enseguida se acercan más al realismo norteamericano (Williams, pero sobre todo Miller). Por otro lado, como demuestra Joffré en otro trabajo (1999), la poética brechtiana llega a los escenarios limeños solo iniciando la década de 1960.

Ciertamente, y a pesar de las abiertamente opuestas interpretaciones al texto final de Salazar Bondy, este interés constante por iluminar la génesis de El rabdomante se justifica plenamente. Es quizás de uno de los textos más representativos de la dramaturgia peruana del siglo $X^{8}{ }^{8}$, más interesante aún si se piensa que se trata de una obra no realista. Se trata, por el contrario, de una historia acerca de un mago capaz de descubrir agua con una varita, que aparece como visitante inusual de un lugar indefinible que debe recordarnos "remotamente a los Andes", y quien se ve enfrentado a autoridades abusivas e ignorantes claramente inspiradas en el abusivo control que ejerce el Estado en zonas rurales del Perú. Ante la incomprensión del Estado, el rabdomante encuentra a los miserables, personajes oprimidos (hasta la supresión de su capacidad lingüística) quienes resultan beneficiados cuando el rabdomante es capaz de encontrar el agua. Lo que sucede después es una secuela de violencia incontrolable en que los miserables, fortalecidos por el agua, matan a las autoridades $y$ al propio rabdomante.

El simbolismo de la pieza es suficientemente sugerente y complejo, pero también suficientemente crudo como para que la aplicación a la realidad circundante opere de forma automática, y es tal vez por ello que esta obra breve (representada probablemente en 35-40 minutos) también

7 Un hallazgo interesante de Gerald Hirschhorn fue un grupo de obras traducidas al español por Salazar Bondy, entre las que se cuenta obras de lonesco, Von Kleist, Gatti y Roussin. 8 Una reciente Antología general del teatro peruano, de Ricardo Silva-Santisteban, considera El rabdomante como una de las obras más representativas de Salazar Bondy y del Perú de la década de 1960. 
puede ser reclamada como una de las imágenes teatrales más cabales que se haya escrito sobre la peruanidad. Así, El rabdomante comienza con una secuencia de búsqueda del agua por parte de los miserables. Una necesidad mayor y su propio beneficio les da su agencia; unas autoridades ladronas, excluyentes, se instalan de inmediato en las antípodas de los miserables. Estos poseen certeza y esperanza, pero desconocen los medios para lograr su causa y, por ello, fracasan constantemente. La búsqueda de agua es, sin dudas, el anhelo central. Mientras tanto, las autoridades (denominados genéricamente como gobernador, ingeniero y portapliegos) irrumpen en la escena para reprobar la búsqueda: "No solo de agua vive el hombre". Ocupados en mantener su propio poder, y ayudados por la ciencia como extensión de ese poder (ingeniero), se instalan en la escena como el bando de los poderosos dominando a los débiles personajes del inicio. En mi lectura, el dilema se muestra con claridad: ante una necesidad y un problema sin solución, solo tenemos estructuras de poder ancladas en discriminación y opresión.

El momento detonante será la insólita aparición del rabdomante. Mago, santón, portando una varita, el rabdomante se propone como la alternativa de resolución del problema. Apoyado sin energía por las autoridades y, luego, urgido por los miserables, el mago rastrea el agua con una varita. La ubica al fin, la percibe, aunque finalmente fracasa: no es capaz de hacerla aflorar. Es apresado y abandona la varita.

Son los miserables, nuevamente solos, quienes al encuentro del objeto mágico se hacen fuertes para dominar al agua. Comienza entonces una espiral de violencia en contra de los opresores del pasado, que culmina con la muerte del gobernador y la persecución de propio rabdomante. La violencia es ciega, no tiene oponentes. El rabdomante espera calmado el fin de su propia vida.

La estructura del drama es lineal y los hechos se suceden con relativa calma. Solo hacia el final se dan saltos en el tiempo y asistimos a la escena final de forma algo precipitada. Los personajes aparecen contrastados, notoriamente, en la forma de usar el español.

En El rabdomante se despliegan una serie de símbolos que conviene examinar más detenidamente. Quiero enfocarme en tres elementos discursivos que considero esenciales en la construcción de la pieza: la alegórica imagen del agua y sus multifacéticas implicancias; la reveladora caracterización del personaje protagónico como un mago ajeno al tiempo y el espacio; y el sistema del tiempo que el relato plantea.

En primer lugar, aunque el signo propuesto como objeto de búsqueda, el agua, no impide una rápida interpretación referida a la realidad socioeconómica concreta del Perú —realidad que aparece detenida en el 
tiempo-, su complejidad es digna de consideración. Además de icónica y referencial, habrá que considerar esta agua como metonimia de la naturaleza misma, la vida y la riqueza. Aquí el agua connota una idea de orden y equilibrio, y una victoria sobre la muerte, sugerida por oposición a la sequía que es sugerida en el inicio de la obra.

Pero también el agua es un símbolo ampliamente interpretable: es sustancia o principio generador, como la ven los griegos y la tradición occidental; es fuente de purificación y alianza, como implica la visión religiosa judeocristiana; pero también es el agua como fin del mundo y lugar de transformación, permanencia o existencia, el agua como objeto de culto en el mundo andino. El agua buscada en El rabdomante participa de estas figuraciones y las excede; deja de ser el simple recurso posible para convertirse en objeto de implicancia cosmogónica, en revelación de una verdad.

Este es ya un programa ideológico que se abre paso además en la construcción de la imagen, pues el agua funciona como verdad, y la verdad como liberación de un pueblo oprimido. Salazar Bondy dota de espesor mayor al múltiple significado del agua, resemantizando el símbolo hasta convertirlo en incitación a la lucha, recurso solo utilizable por los pueblos mismos, y totalmente librado al uso que de él quieran hacer. No en vano, hacia el final de la pieza, cuando las acciones violentas se han llevado a cabo, el dramaturgo hace concluir a uno de sus personajes con precisa contradicción: "El agua se volvió fuego".

En segundo lugar, destaca la caracterización del rabdomante, personaje extraño hasta en la propia denominación, pero poseedor de un don de adivinación que puede solucionarlo hasta lo que parece imposible. El personaje en sí concentra numerosas marcas discursivas: es un ser dotado de dones extraordinarios:

Alumbro las aguas subterráneas, descargo las fuerzas ocultas, descorro las costuras de la tierra seca. Soy un zahorí (p. 294).

Es a la vez capaz de encontrar el agua, como un mago antiguo o un chamán, poseedor de un poder que se insinúa oculto y tradicional. Pero, además, es un sujeto histórico consciente de la necesidad de su presente y de la utilidad de su saber. Salazar Bondy nos presenta un rabdomante que es luchador contra sequías y buscador desinteresado de la verdad. Cuando una de las autoridades se ofrece a comprar su talento, arguye: "Se ha equivocado usted conmigo. No soy comerciante" (p. 303).

Oxímoron encarnado, en el personaje del rabdomante coinciden las categorías más contradictorias: caracteriza un saber natural, antihistórico, que luego se muestra como eventual conocedor de la ciencia más moderna. 
Así, en contraste con el aparente "pensamiento mítico" del inicio, el personaje explica su propia magia en términos que parecen aludir a la ciencia. Interrogado por las autoridades sobre la naturaleza de su capacidad, explica: "[Con mi acción] Se produce el efecto de Quincke, ¿entiende?, y en el subsuelo se desatan corrientes eléctricas. Estas, como es lógico, provocan la aparición de campos magnéticos" (p. 298). Al margen de si esta descripción es apropiada a la ciencia natural o no, es interesante destacar el contraste que propone Salazar Bondy para su personaje central. El lenguaje que evocan estas líneas descubre al rabdomante como un sujeto moderno, científico a su modo, o poseedor de una ciencia que le permite adentrarse en la realidad.

Desde luego, también aparece como rasgo la individualidad del personaje. Es un luchador fundamentalmente libre, único, capaz de acciones desprendidas, al extremo de permitir su propia muerte. Por la misma razón también es una víctima de la incomprensión y la violencia. Su doble despliegue es asimismo contradictorio: es social por vocación pero individual en sus acciones, y este aislamiento es la situación que finalmente lo conduce a la muerte. Al no afiliarse a las acciones de los miserables violentos ni a las de las autoridades perseguidas, el rabdomante resulta un ser intermedio, doblemente alienado.

Finalmente, es también contradictoria su función de donador/buscador de agua, en tanto símbolo de la vida, pues a la vez el relato lo hace aparecer como indirecto portador de venganza y muerte, que asume como una consecuencia natural de su acción inicial y ante las cuales no opone mayor resistencia.

Pero si hay un elemento discursivo revelador del programa ideológico y representacional de la obra es el tratamiento del tiempo escénico, es decir, del tiempo que la historia presenta. De inicio, la pieza se instala en una imprecisión temporal histórica, deliberada y requerida para la puesta en escena. Las indicaciones del inicio presentan una abolición del pasado como posible referente histórico, lo que acentúa la identificación con el tiempo presente, que es el tiempo de la representación. Este tiempo sin tiempo del inicio, sin especificidad, es un inmovilismo que parece insondable, una suerte de estancamiento milenario. La obra así se propone como un eterno presente. En mi opinión, Salazar Bondy busca deshistorizar su relato adrede y logra impregnar la escena de una especie de mitificación. El tiempo muerto o, ralentizado al extremo, es el momento en que empieza la acción. Y luego, en un contraste singular, el arco temporal de la obra nos lleva al poco a poco al advenimiento de un nuevo orden, esto es, a la abolición del tiempo antiguo, o tiempo sin avance, lo que da un acelerado avance de la trama. El tiempo entonces tiende a acelerarse, y el segmento 
final de la pieza despliega momentos con sucesivos saltos cronológicos y acciones sin control. Incluso, en una alegoría directa a la rotundidad del cambio, el espacio descrito al inicio se ve alterado (florecen los pastizales) y el nuevo tiempo llega con caracteres diferenciadores bastante esclarecidos: los miserables pasan a ser los fuertes, las autoridades devienen los débiles.

La secuencia final de la obra se abre con un salto muy rápido en que hay una elipsis en la trama. Entre la consecución del agua y la persecución de los enemigos han mediado otros "momentos" que la obra elude y a los que se refieren algunos personajes en pasado: "Vio cómo estrangularon al gobernador". Este final abierto, funciona como contrapunto una vez más entre tiempo detenido y marcha violenta y es, a mi entender, la marca distintiva más clara de que nos hallamos ante una obra no realista, pero sustentada en un discurso de liberación social. Así, este tiempo de la obra se instala enfrentado a dos otras posibles temporalidades: una conservadora y otra cíclica. El tiempo de El rabdomante no es el tiempo restaurado del discurso conservador que regresa al orden inicial (no hay orden inicial, pues se confunde con lo desconocido); pero tampoco es el tiempo cíclico, el del eterno retorno, o circular que tanto ha explotado la poética del absurdo para certificar la imposibilidad de cambios en la realidad. Los toques de absurdismo de la obra (en el lenguaje y en la corporalidad de los personajes) son únicamente un matiz que ayuda a distanciarse de la situación descrita, disociando elementos coyunturales para conseguir un relato más esquemático o, mejor dicho, más didáctico ${ }^{9}$. El tiempo proyectado al futuro se muestra dialécticamente, entendiendo por tal la resolución de situaciones históricas insertadas en el devenir histórico, al margen del cual simplemente no podrían existir. La estructura del tiempo resuelve así una de las dudas mayores que la obra ha ofrecido a sus intérpretes durante mucho tiempo: Salazar Bondy en El rabdomante no está retrocediendo ideológicamente hacia los confines del absurdismo: su apuesta por el cambio social es nuevamente notoria en esta obra. La propia trama revela que la convicción del dramaturgo seguía estando del lado del cambio completo de la situación opresiva figurada en la apertura del relato. Fuera del pesimismo que puede transmitir el texto dramático, la obra se plantea como una guía casi didáctica del camino a seguir en el proceso de liberación de los oprimidos en un espacio social alegóricamente reconocible como el Perú.

9 Estoy aludiendo aquí al concepto de pieza didáctica siguiendo la estética brechtiana, las piezas breves para adoctrinar con una intención moral o política. Para una discusión detallada del tema, ver Jameson, Brecht and Method. 


\section{Entre Lima la horrible y un buscador de agua}

Desde luego, he de decir que la discusión que esta obra abre, por inusual que sea, no deja de ser también central en la teatralidad peruana. Precisamente desde El rabdomante, una estirpe de obras sin tregua ha venido preguntándose por la compleja violencia de nuestro tejido cultural y nuestros desencuentros entre modernidad e identidad. Collacocha de Solari Swayne, La hija de Lope de Sara Joffré, Qué sucedió en Pazos de Vega Herrera, Atusparia de Ribeyro, El caballo del Libertador de Alfonso Santistevan, entre otras, contienen todas ellas claves para repensar la persistencia de modelos coloniales de poder que aún rigen, se reconstruyen, permanecen en el Perú. Pero pocas experiencias escriturarias desde el teatro han querido volver a la pregunta central: ¿cuál es el origen de tal violencia, de tal desencuentro estructural en la nación?

Así, el punto de mira inicial que está en relación directa a El rabdomante es lo que puede ser llamado un sustrato de colonialidad en la experiencia histórica peruana que explica el pasado reciente, y también el remoto, y que aparece como telón de fondo contra el que Salazar Bondy proyecta su ficción. Como es fácil advertir, estamos hablando de las dificultades culturales y sociales, nacidas de la historia peruana posterior a la Conquista, y que tienen un último anclaje en la persistencia de modos coloniales de dominación. Los personajes de El rabdomante se enfrentan directamente con tales imágenes que nos remiten a las bases de la dominación de tipo colonial que emparenta con nuestra historia reciente con nuestra experiencias desde el inicio de la modernidad temprana.

Como se sabe, las formas de dominación de la colonialidad (la matriz colonial del poder, en palabras de Aníbal Quijano) se expresa en cuatro aspectos: el control de la economía, la fuerza de trabajo y la tierra; el control del poder y la institucionalidad; la división de géneros; y el control de la subjetividad y el conocimiento, por ejemplo, a través de la educación. La matriz colonial del poder es una noción válida para explicar la sociedad de castas y privilegios que aparece retratada con claridad en todos los hechos y situaciones discutidos en Lima la horrible y recreados en El rabdomante.

La complejidad de la experiencia cultural peruana, nacida del trauma de la desaparición de una civilización, la imposición de modelos foráneos de dominación, y la conciliación casi imposible de los contrarios hasta la fecha, explica la raíz de la arcadia colonial que Salazar Bondy creía haber atrapado en su magnífico ensayo. Incluso se puede decir que en la experiencia violenta peruana del fin del siglo XX hay una presentación de las constantes coloniales de su propia historia, como también se ha hecho explícito en el trabajo de pensadores como Flores Galindo en Buscando 
un inca. El proyecto de conquista y sojuzgamiento de las culturas aborígenes, entendido como un proyecto de modernización/civilización de los atrasados y bárbaros, alcanza sin duda al conflicto armado interno, a la inestabilidad social presente, para condensarse con las medidas represivas tomadas por el Estado en contra de las comunidades rurales a las que juzgaba como inferiores y bárbaros. No en vano, en mi perspectiva, Salazar Bondy hace finalizar el relato en un estallido social, violento, que desaparece incluso al rabdomante.

Sin embargo, es necesario recordar que la misma matriz colonial del poder que representan las autoridades también es reconocible en el otro bando, cuando, por ejemplo, los arrasamientos poblacionales llevados adelante por el marxismo-maoísmo senderista se llevaron de encuentro a grupos de campesinos que no les eran favorables. La retórica de la salvación, con su lógica de opresión y explotación que alimenta todo proyecto de modernidad-colonialidad, era muy fácil de advertir en ambas perspectivas.

En mi lectura de Lima la horrible y El rabdomante, el sustrato de colonialidad permitiría destacar la estructura social e histórica de la nación peruana que aparece a contraluz en ambos textos, y así intentaría elucidar las matrices culturales que sostienen sus estructuras políticas y económicas que aparecen representadas y discutidas.

Se trata de un macrodiscurso que está escondido debajo de nuestras cotidianas batallas, pero que resiste su descubrimiento, crítica y necesaria desactivación. Un macrodiscurso de teatralidad, la colonialidad incorporada en las performances culturales, que nos habla antes de que nosotros hablemos, nos pauta los modos del cuerpo, de la voz, de los gestos (los modos sumisos o autoritarios en la obra, son, primero que nada, modos en que el cuerpo ocupa el espacio). El macrodiscurso estético que digita nuestras elecciones estéticas, nuestra noción de teatralidad, en este caso, también es parte de esa experiencia. Ese macrodiscurso de la colonialidad es el centro de la experiencia del desasosiego nacional, ese luto permanente que a veces creemos solo individual y pasajero.

¿Cómo discutir este macrodiscurso que es una colonialidad del ser? ¿Por dónde empezar a presentarlo, o a representarlo? ¿Cómo hace un lápiz para empezar a trazar un vastísimo dibujo a escala del sol?

Cuando, en la escena final de El rabdomante, el personaje central acepta su destino de morir, en mi lectura, también acepta que la posibilidad de enterrar para siempre a la arcadia colonial, y dará como consecuencia una nueva etapa en el ciclo histórico de la discusión sobre la colonialidad peruana. 
Es cierto que después de la escritura de Lima la horrible y El rabdomante se ha seguido abriendo paso algo que podemos Ilamar una colonialidad supérstite (usando el término acuñado por Mariátegui) en la sociedad peruana. Han mediado ya cinco décadas de cultura y violencia peruanas que no han sido, para nuestro pesar, suficientes para llevarnos a la consciencia de la necesidad de responder a las interpelaciones que nos hace nuestro experiencia social, aquellas preguntas sobre la raíz colonial de nuestros desencuentros. El hecho de que el personaje del rabdomante parezca anticipar esa violencia no tiene por qué llamar a extrañeza: el programa ideológico de la obra conectado a la experiencia política e histórica que están detrás de su escritura, la colonialidad supérstite ante la cual quiere reaccionar también en Lima la horrible, parece que no podían desembocar sino en una violencia generalizada.

\section{Una utopía de socialismo mágico}

"Cuánto entendí el socialismo, no lo sé. Pero no mató en mí lo mágico». José María Arguedas, "Discurso de aceptación del Premio Garcilaso de la

Vega»

He querido retomar literariamente el término utopía como una provocación de entendimiento que se dispara a raíz de revisitar El rabdomante tantos años después de su escritura. Aunque suene solo a una intuición, considero posible tender de un puente de pensamiento sobre lo peruano entre quienes fueron, sin duda, dos de los más grandes intelectuales peruanos. No todos los intelectuales y artistas peruanos, lo sabemos, lo son realmente del Perú, ni hacen de este país desgarrado y complejo su pasión, su vida, y en gran medida su muerte. Hubo entre Salazar Bondy y Arguedas muchas polémicas, largamente documentadas, pero hubo también entre ellos un programa cultural común: el de hacer literatura de, con y para el Perú.

Es importante poner de manifiesto esta relación en mi conclusión a esta visita a El rabdomante, a la luz de la señera intuición del autor de Los ríos profundos. El rabdomante también podría funcionar como una metáfora de la búsqueda urgente de un bien social en el Perú, a través de un ser extraordinario expuesto ante una realidad igualmente extraordinaria. Esta búsqueda deberá quebrar el sistema que oprime, y develar la conciencia misma del bien, esa agua por la que todos esperan. El rabdomante - mago, sabio, intelectual o artista, o una síntesis de todos- puede (¿debe?) reconocerse como un puente entre dos mundos divorciados, con temporalidades que no se encuentran, y someterse a la vez a las leyes dialécticas de la historia: él solo será un momento en el proceso de cambio, la Historia no acabará con él, pero su obra tomará el cariz de una gesta cultural. 
Por otro lado, en esta utopía mágica, extraña aún para casi todos, complejamente metafórica, quedará todavía por revelar la praxis misma, que deberá ser un hecho mítico y real al mismo tiempo, o un reencuentro con la experiencia de lo posible. Esa utopía del cambio social es también un exigido y sugerente encuentro de dos visiones aparentemente opuestas de la realidad: una visión dialéctica occidental concordada esta vez, con una visión del mundo inasible y mágico proveniente de la autoctonía andina. No serán suficientes una u otra por separado y, a la vez, la utopía no se enunciará ya solo como lo que no ha de suceder, sino, sobre todo, como aquello que aún no ha sucedido. Solo entonces, una suerte de rabdomancia podrá encontrar su lugar en estas tierras. 


\section{REFERENCIAS BIBLIOGRÁFICAS}

Arguedas, J. M. (1996). Discurso de aceptación del Premio Garcilaso de la Vega. En El zorro de arriba y el zorro de abajo, Madrid: Allca XX y Fondo de Cultura Económica.

Caballero, J. (1975). El teatro de Sebastián Salazar Bondy. Lima: Librería García Ribeyro.

Hirschhorn, G. (Dir.). (2005). Sebastián Salazar Bondy. Pasión por la cultura. Lima: Institut Français d'Études Andines.

Joffré, S. (1993). Críticos comentaristas y divulgadores. Lima: Lluvia Editores. Luchting, W. (1971). Julio Ramón Ribeyro y sus dobles. Lima: Instituto Nacional de Cultura.

Oviedo, J. M. (1967). Sebastián Salazar Bondy en su teatro. Lima: Moncloa Editores.

Salazar Bondy, S. (1967). El rabdomante. En Obras completas de Sebastián Salazar Bondy (tomo II). Lima: Moncloa Editores.

(1958). Seis juguetes. Lima: Nuevos Rumbos.

Susti, A. (2014). La luz tras la memoria. Antología de artículos críticos de Sebastián Salazar Bondy. Lima: Lápix Editores.

Vargas Llosa, M. (1967). Sebastián Salazar Bondy y la vocación del escritor en el Perú. Lima: Moncloa Editores.

Vargas Salgado, C. (abril de 2015). ¿Nueva dramaturgia o nuevos dramaturgos? Teatralidades, vol. 1, nro. 1. Lima, Washington. 